\section{(6) OPEN ACCESS}

\title{
FIFA Women's World Cup 2011: Pre-Competition Medical Assessment of female referees and assistant referees
}

\author{
Dagmar I Keller, ${ }^{1,2}$ Mario Bizzini, ${ }^{3}$ Nina Feddermann, ${ }^{4}$ Astrid Junge, ${ }^{3}$ Jiri Dvorak $^{3,5}$
}

\begin{abstract}
${ }^{1}$ Cardiology Department, University Hospital Zürich, Zürich, Switzerland

${ }^{2}$ Spinal cord injury center, University Hospital Balgrist, Zürich, Switzerland

${ }^{3}$ FIFA Medical Assessment and Research Centre (F-MARC) and Schulthess Clinic, Zürich, Switzerland

${ }^{4}$ Neurology Department, University Hospital Zürich, Zürich, Switzerland ${ }^{5}$ Fédération Internationale de Football Association (FIFA) and Schulthess Clinic, Zürich, Switzerland
\end{abstract}

\section{Correspondence to} Dr Dagmar I Keller, Cardiology Department, University Hospital Zuerich, Raemistrasse 100, 8091 Zürich, Switzerland; dagmar.keller@usz.ch

Received 4 June 2012 Revised 15 August 2012 Accepted 17 August 2012 Published Online First 12 September 2012

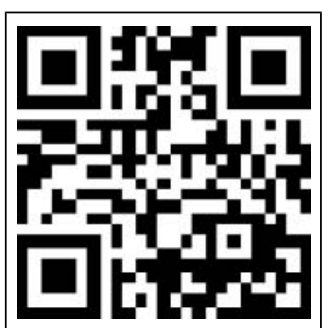

Scan to access more free content

To cite: Keller DI, Bizzini M, Feddermann $\mathrm{N}$, et al. Br J Sports Med

2013;47:179-181.

\begin{abstract}
Background Precompetition screening was implemented for male referees during the 2010 Fédération Internationale de Football Association (FIFA) Word Cup. In contrast, female football referees have been neglected in this respect although they experience similar physical work loads compared to male referees. Methods The standardised football-specific PreCompetition Medical Assessment (PCMA) was performed in 51 referees and assistant referees selected for the 2011 FIFA Women's World Cup.

Results Family history for sudden cardiac death (SCD) was positive in four referees (7.8\%), but cardiac examinations did not reveal any pathological findings. Training-unrelated ECG changes were identified in three referees $(5.9 \%)$, all without correlates in

echocardiography or clinical examination. Most common echocardiography findings $(66.6 \%, n=34)$ were

asymptomatic tricuspid and mitral regurgitations.

Conclusions During the present screening, no elite female referee was identified being at risk for SCD, and no referee had to be excluded from participating in the 2011 FIFA Women's World Cup.
\end{abstract}

\section{INTRODUCTION}

Preparticipation screening programmes to prevent sudden cardiac death (SCD) among young athletes have been accepted based on numerous proposals. $^{1-3}$ For elite male football players, the Fédération Internationale de Football Association (FIFA) introduced a standardised football-specific Pre-Competition Medical Assessment (PCMA) starting in the 2006 FIFA Word Cup ${ }^{4}$ and subsequently introduced it for female players; it is now mandatory in all FIFA competitions. ${ }^{5}$ PCMA was implemented for male referees selected for 2010 FIFA World Cup and data were published recently. ${ }^{6}$ Concerning female referees no data about PCMA have systematically been assessed, yet. Female referees experience similar physical work loads compared to male referees and therefore are at the same risk for SCD as a normal sport population or male referees. In this study, the cardiovascular findings obtained in the PCMA of female referees and assistant referees selected for the FIFA Women's World Cup 2011 were analysed.

\section{METHODS}

The PCMA protocol includes medical history, general physical examination, 12-lead resting ECG and transthoracic echocardiography. The standardised PCMA's were performed at the FIFA headquarter in Frankfurt from 17 to 19 June 2011. All subjects gave written informed consent. Experienced physicians including a cardiologist (DIK) conducted all examinations. ECG's were analysed according to current recommendations of the European Society of Cardiology (ESC). Findings were grouped into common/training-related and uncommon/training-unrelated. ${ }^{7}$ Transthoracic echocardiographies were performed and interpreted based on current recommendations. ${ }^{8}$ Data were acquired for each referee on the 'Pre-Competition Medical Assessment-Individual Report' sheet, provided by F-MARC, Medical Research Office, Schulthess Clinic, Zuerich, Switzerland. Mean values and SDs were determined on the Microsoft Excel programme.

\section{RESULTS}

Nineteen female referees and 32 assistant referees underwent precompetition screening. Baseline characteristics were of an average age of $33.2(\mathrm{SD}=3.8$, range 25-41) years, average height of 166 $(\mathrm{SD}=5.4$, range $150-181) \mathrm{cm}$, average weight of $60.1(\mathrm{SD}=5.5$, range $48-73) \mathrm{kg}$ and average body surface area of $1.7(\mathrm{SD}=0.1$, range $1.45-1.93) \mathrm{m}^{2}$.

In family history, 19 (37\%) referees reported hypertension, $11(21.5 \%)$ diabetes mellitus, nine $(17.6 \%)$ coronary heart disease (CHD), five (9.8\%) stroke and two (3.9\%) valvular heart disease. Three (5.9\%) referees reported familial SCD, another one (2\%) reported SCD due to CHD. In general medical history one (2\%) referee reported diabetes mellitus type I and another (2\%) a suprarenal hyperplasia. Allergies to pollen, food or antibiotics were common $(\mathrm{n}=17 ; 33.3 \%)$, three $(5.9 \%)$ referees had exercise-induced asthma. No cardiovascular medication was reported but insulin. Non-steroidal painkillers were used regularly by $23(45 \%)$ referees and $11(21.5 \%)$ took antihistaminics.

Right arm systolic blood pressure was on an average 107.1 ( $\mathrm{SD}=9.9$, range $90-131) \mathrm{mm} \mathrm{Hg}$, diastolic $67.3(\mathrm{SD}=10.2$, range $48-95) \mathrm{mm} \mathrm{Hg}$. Left arm systolic blood pressure was on an average 105.5 (SD=10.1, range 84-141) $\mathrm{mm} \mathrm{Hg}$, diastolic $67.2(\mathrm{SD}=9.2$, range 49-95) $\mathrm{mm} \mathrm{Hg}$. The average heart rate at rest was $59.8(\mathrm{SD}=9.9$, range $47-91)$ bpm.

Auscultation revealed in 16 (31\%) referees a systolic heart murmur without echocardiography finding, though considered as 'functional'. A mild systolic murmur was found in one referee $(2 \%)$ with mild central aortic regurgitation with a tricuspid aortic valve with slight asymmetry of the cusps, in one $(2 \%)$ with mild-to-moderate mitral regurgitation due to discrete myxoid changes without 
Table 1 Number and percentages of referees with echocardiographic findings

\begin{tabular}{ll}
\hline Transthoracic echocardiography & Referees (number/percentage) \\
\hline Tricuspid regurgitation & $25 / 49$ \\
Mitral regurgitation & $9 / 17.6$ \\
Aortic regurgitation & $1 / 2$ \\
Ventricular septum defect & $2 / 3.9$ \\
\hline
\end{tabular}

mitral valve prolaps and in one (2\%) with a small ventricular septum defect (VSD). In one referee (2\%) with a very mild systolic murmur, a very small VSD was detected.

Echocardiography findings are summarised in table 1 . No referee revealed a hypertrophic left ventricle (LV) or cardiomyopathy. Average LV values were: interventricular septum diastolic (IVSd) $7.9(\mathrm{SD}=1$, range 6-10) $\mathrm{mm}$, posterior wall diastolic (PWd) $8.3(\mathrm{SD}=1$, range 6-10) $\mathrm{mm}$, LV muscle mass index $71.5(\mathrm{SD}=11.5$, range $48-95) \mathrm{g} / \mathrm{m}^{2}$ and $\mathrm{LV}$ enddiastolic diameter index (LVEDI) $51.5(\mathrm{SD}=9.1$, range $35-73) \mathrm{mm} / \mathrm{m}^{2}$. $\mathrm{LV}$ ejection fraction was on average $67.6(\mathrm{SD}=4.2$, range $60-74)$ $\%$. All had normal diastolic function (E/A 1.8, $\mathrm{SD}=0.3$, range 3.1-1.2).

Findings of the 12-lead resting ECG are shown in table 2. Three $(5.9 \%)$ referees revealed training-unrelated changes, which were T-wave inversions in all cases.

\section{DISCUSSION}

This study presents the first data of precompetition screening of female football referees selected for the 2011 FIFA Women's World Cup. No elite female referee was identified being at risk for SCD and had to be excluded from participation.

The four $(7.8 \%)$ referees with a positive family history of SCD revealed no abnormal findings in clinical examination. In contrast, no history of SCD was obvious in the male referees PCMA. ${ }^{6}$ This difference might be explained by lacking information about the family history in some subjects on the one hand and lacking data about the correct cause of death on the other hand. One (1.9\%) referee with diabetes mellitus type I had a positive family history for diabetes which is inline with the male referee assessment. ${ }^{6}$

In personal history allergies were most frequently found $(n=17,33.3 \%)$, three $(5.9 \%)$ had exercise-induced asthma (EIA). The incidence of EIA is supposed to be higher in football players compared to water sports athletes and lower compared to runners. ${ }^{9}$ Two (3.9\%) referees had isolated increased diastolic blood pressure (94-95 mm Hg) of which one took regular nonsteroidal painkillers which might have a negative effect on blood pressure. ${ }^{10}$ Both were advised to follow-up blood pressure measurement.

Systolic heart murmurs were the most common cardiac finding whereas echocardiography revealed in $34(\mathrm{n}=66.6 \%)$ referees a tricuspid or mitral regurgitation. In comparison with male referees no LV hypertrophy or cardiomyopathies were identified. ${ }^{6}$ A hypermobile atrial septum was found in four (7.8\%), an atrial septum aneurysm in two (3.9\%) and small VSD in two $(3.9 \%)$ whereas none of these findings were found in the male referees. ${ }^{6}$ Uncommon T-wave inversion was identified in three $(5.9 \%$ ) referees (table 2), of which all had a negative family history for SCD. The incidence was higher compared to male referees with a $3.3 \%$ incidence of $\mathrm{T}$-wave inversion in inferior leads. ${ }^{6}$ One (1.9\%) referee revealed isolated T-wave
Table 2 Number and percentages of referees with ECG findings

\begin{tabular}{ll}
\hline 12-Lead resting ECG & $\begin{array}{l}\text { Referees (number/ } \\
\text { percentage) }\end{array}$ \\
\hline Training-related ECG changes and common & \\
Sinus bradycardia & $28 / 54.9$ \\
First-degree AV-block & $2 / 3.9$ \\
Notched QRS in V1 or incomplete RBBB & $7 / 13.7$ \\
Early repolarisation & $2 / 3.9$ \\
Isolated QRS voltage criteria for LV hypertrophy & $1 / 2$ \\
Training-unrelated ECG changes and uncommon & \\
T-wave inversion & \\
$\quad$ Isolated in V2 & $1 / 2$ \\
$\quad$ Isolated in lead aVL & $1 / 2$ \\
In lead III and aVL & $1 / 2$ \\
\hline AV, atrioventricular; LV, left ventricular; RBBB, right bundle branch block.
\end{tabular}

inversion in aVL; echocardiography showed mild-to-moderate mitral regurgitation due to discrete myxoid changes, and normal LV parameters. She was advised for yearly follow-up echocardiography which will be performed in her home country. One (1.9\%) referee showed isolated T-wave inversion in V2 without Brugada-like pattern; in contrast male referees revealed a higher incidence of Brugada-like pattern $(4.4 \% ; n=7)$. In the age group of 35 years or more in which SCD is most commonly associated to $\mathrm{CHD}$, all referees were completely asymptomatic and revealed no uncommon findings in 12-lead resting ECG or echocardiography except for one (1.9\%) referee with isolated T-wave inversion in lead III. No exercise ECG was performed in the present study.

In this study the standardised PCMA's have been performed shortly before the 2011 FIFA Women's World Cup. Precompetition and preparticipation screening should be performed in every referee or athlete in general. Some of the referees did already profit from previous screening in their home countries, which contributes to this selection of 'healthy' referees.

\section{CONCLUSIONS}

PCMA is a feasible tool to identify referees at risk for SCD and has to be repeated on a regular base. No elite female referee was identified being at risk for SCD and had to be excluded from participating in the 2011 FIFA Women's World Cup.

Acknowledgements We gratefully acknowledge the FIFA for the funding of this study. We greatly appreciate the support of and collaboration with Mrs Sonia Denoncourt, Head of Women's FIFA Refereeing and of Mr Edgar Strelsov, FIFA Refereeing Department.

Contributors DIK performed cardiac examination, data analysis and manuscript writing. MB and NF: performed clinical examination. AJ and JD instrumented the study design, provided support and feedback at all stages of the study and heavily contributed to writing and reviewing the manuscript. All coauthors reviewed and improved the study.

\section{Competing interests None.}

\section{Patient consent Obtained.}

Ethics approval Institutional Review Board.

Provenance and peer review Not commissioned; externally peer reviewed.

Open Access This is an Open Access article distributed in accordance with the Creative Commons Attribution Non Commercial (CC BY-NC 3.0) license, which permits others to distribute, remix, adapt, build upon this work non-commercially, and license their derivative works on different terms, provided the original work is properly cited and the use is non-commercial. See: http://creativecommons.org/ licenses/by-nc/3.0/ 


\section{REFERENCES}

1 Corrado D, Pelliccia A, Bjornstad HH, et al. Cardiovascular pre-participation screening of young competitive athletes for prevention of sudden death. Eur Heart $J$ 2005;26:516-24.

2 Borjessen M, Urhausen A, Kouidi E, et al. Cardiovascular evaluation of middle-aged/senior individuals engaged in leisure-time sport activities. Eur J Cardiovasc Prev Rehabil 2011;18:446-58.

3 Maron BJ, Thompson PD, Ackermann MJ, et al. Recommendations and considerations related to preparticipation screening for cardiovascular abnormalities in competitive athletes. Circulation 2007;115:1643-55.

4 Dvorak J, Grimm K, Schmied C, et al. Development and implementation of a standardized precompetition medical assessment of international elite football players-2006 FIFA World Cup Germany. Clin J Sport Med 2009;19:316-21.
5 Dvorak J, Grimm K, Schmied C, et al. Feasibility of precompetition medical assessment at FIFA World Cups for female youth players. Br J Sports Med. Published Online First 20 October 2011. doi:10.1136/bjsports-2011-090374.

6 Bizzini M, Schmied C, Junge $A$, et al. Precompetition medical assessment of referees and assistant referees selected for the 2010 FIFA WORD CUP. Br J Sports Med 2012;46:374-6.

7 Corrado D, Pelliccia A, Heidbuchel $H$, et al. Recommendations for interpretation of 12-lead electrocardiogram in the athlete. Eur Heart J 2010;31:243-59.

8 Lang RM, Bierig M, Devereux RB, et al. Recommendations for chamber quantification. J Am Soc Echocardiogr 2005;18:1440-63.

9 Sidiropoulou MP, Kokaridas DG, Giagazoglou PF, et al. Incidence of exercise induced asthma in adolescent athletes under different training and environmental conditions. J Strength Cond Res 2012;26:1644-50.

10 Grossman E, Messerli FH. Drug-induced hypertension: an unappreciated cause of secondary hypertension. Am J Med 2012;125:14-22. 